\title{
Effect of testosterone, raloxifene and estrogen replacement on the microstructure and biomechanics of metaphyseal osteoporotic bones in orchiectomized male rats
}

\author{
E. K. Stuermer $\cdot$ S. Sehmisch $\cdot$ M. Tezval $\cdot$ H. Tezval $\cdot$ \\ T. Rack · J. Boekhoff $\cdot$ W. Wuttke $\cdot$ T. R. W. Herrmann · \\ D. Seidlova-Wuttke $\cdot$ K. M. Stuermer
}

Received: 29 July 2008 / Accepted: 13 January 2009 / Published online: 17 February 2009

(C) The Author(s) 2009. This article is published with open access at Springerlink.com

\begin{abstract}
Introduction Currently, osteoporosis research is rarely undertaken in males but an increase in male life expectancy in the company of hypogonadism suggests the necessity for potential therapeutic options.

Materials and methods In this study, the changes in bone structure under standardized testosterone- $(\mathrm{T})$, raloxifene$(\mathrm{R})$ and estrogen (E)-supplemented diets were analyzed in osteoporotic castrated male rats.

Results Unexpected biomechanical results could be only explained by the histomorphometry, but not by BMD measurements obtained from the $\mathrm{qCT}$. All tested substances showed a significant improvement in the trabecular network (trabecular bone area for C: $2.55 \mathrm{~mm}^{2}, \mathrm{~T}: 4.25 \mathrm{~mm}^{2}$, $\mathrm{R}: 4.22 \mathrm{~mm}^{2}$ and E: $4.28 \mathrm{~mm}^{2}$ ), and suggests that the bone structure was preserved. For the metaphyseal cortical bone, a significant loss was detected in T (CBP: 18.7\%) compared to R (CBP: $30.0 \%$ ), E (CBP: 26.8\%) and even to the osteoporotic control (CBP: 28.6\%). This explains the observed early mechanical final failure after $\mathrm{T}$ supplementation. However, due to the preserved trabecular bone in $\mathrm{T}$, the occurrence of the first microfractures $(y L: 49 \pm 21.4 \mathrm{~N}$ )
\end{abstract}

E. K. Stuermer $(\bowtie) \cdot$ S. Sehmisch · M. Tezval · T. Rack ·

J. Boekhoff · K. M. Stuermer

Department of Trauma and Reconstructive Surgery,

Georg-August-University of Goettingen,

Robert-Koch-Str. 40, 37099 Goettingen, Germany

e-mail: e.k.stuermer@med.uni-goettingen.de

W. Wuttke · D. Seidlova-Wuttke

Department of Clinical and Experimental Endocrinology,

Georg-August-University of Goettingen, Goettingen, Germany

H. Tezval · T. R. W. Herrmann

Department of Urology,

Hannover Medical School, Hannover, Germany was significantly later than in the osteoporotic control (yL: $39.5 \pm 15.5 \mathrm{~N}$ ). Raloxifene performed well in hindering the bone loss associated with osteoporosis. However, its effect (yL: $83.3 \pm 16.5 \mathrm{~N}$ ) did not approach the protective effect of $\mathrm{E}(\mathrm{yL}: 99.2 \pm 21.1 \mathrm{~N})$.

Conclusion Testosterone only preserved the deterioration of the trabecular bone but not of the cortical bone. Raloxifene prevented the bone loss associated with osteoporosis at all bony structures. This effect did not approach the protective effect of estrogen on trabecular bone, but it is more suitable for male individuals because it has no feminizing effects on the subject.

Keywords Osteoporosis - Testosterone $\cdot$ Raloxifene . Fracture risk $\cdot$ Hypogonadism $\cdot$ Bone

\section{Introduction}

Osteoporosis has become a pertinent topic in public health today, primarily due to the ever increasing elderly population. Many of the current therapies target postmenopausal osteoporosis $[1,2]$, where estrogens have been shown to have potent anti-osteoporotic properties. However, an increase in life expectancy in males also suggests the necessity to develop potential alternative therapies since estrogens cannot be used in males because of their feminizing side effects. Osteoporosis research is rarely undertaken in males and there are few therapeutic options. Testosterone (T) is an essential hormone for maintenance of bone mass and androgens have anti-osteoporotic properties [3, 4]. However, the clinical significance of testosterone substitution in osteoporotic men with hypogonadism is still undefined. It is believed that estrogens mediate the primary bone-sparing effects of androgens only after aromatization [5]. 
Aromatase gene expression and activity has been demonstrated in bones of male humans and rodents [6-8] Aromatase knock-out mice, as well as estrogen receptor $\alpha$ knock-out mice develop osteoporosis [7, 8]. Additionally, osteoblasts and osteoclasts were equally active in both control and testosterone-treated groups, while a reduction in their activities was associated with estrogen- and raloxifene-supplemented diets [6].

In males, osteoporosis occurs primarily due to slowly deteriorating testicular testosterone production. Therefore, $\mathrm{T}$ supplementation presents itself as an alternative treatment that was tested in the present study. In recent years, the discovery of selective estrogen receptor modulators (SERMs) has led to the availability of substances, which do not affect the mammary glands and gonads, but exert estrogenic, positive effects in bone. One such substance is raloxifene (R), which proved to have potent anti-osteoporotic effects in postmenopausal women $[9,10]$. $R$ appears to have no feminizing effect or negative effects on male gonads [11]. Therefore, $\mathrm{R}$ was also tested in this study.

The castrated rat is an established model of osteoporosis $[12,13]$ and these animals develop substantial osteoporosis with the highest degree occurring in the metaphyseal tibia [14]; after 3 months, bone mass will decrease to about $35 \%$ in male animals $[14,15]$. Consequently, bone density measurements are performed at the femoral neck for humans and in the proximal tibia for rats. The $\mathrm{qCT}$ is an established method used to quantify the effect of anti-osteoporotic agents in vivo [2, 16, 17]. Post-mortem microradiographs from undecalcified histological sections provide higher local resolution. Information about the trabeculae (i.e., number, length, width, localization etc.), and changes in cortical bone can also be obtained in detail.

\section{Materials and methods}

Animals and chemicals

The study protocol was approved by the regional government and conformed to German animal protection laws (permission Az: 509.42502/01-02.98 District Government of Braunschweig).

Forty-four 3-month-old male Sprague-Dawley rats (Winkelmann, Borken, Germany) weighing 220-260 g were orchidectomized under Rompun/Ketanest anesthesia $(3.5 \mathrm{~V} / \mathrm{V}, 1 \mathrm{ml} / \mathrm{kg} \mathrm{BW})$. After the operating procedure, animals were divided into four groups: Group I received phytoestrogen-free pelleted food (where protein supplementation was substituted with potato proteins); Group II received phytoestrogen-free food supplemented with $\mathrm{T}$ (in the form of testosterone propionate) with the average intake of $50 \mathrm{mg}$ T/day; Group III received phytoestrogen-free food supplemented with $\mathrm{R}$ where the average intake was $3.35 \mathrm{mg} \mathrm{R} /$ day; Group IV received phytoestrogen-free food supplemented with $\mathrm{E}$ (in the form of estradiol benzoate), where the average food and $\mathrm{E}$ intake per animal per day was $20 \mathrm{~g}$ and $0.5 \mathrm{mg}$, respectively.

Drugs were used in established concentrations $[2,6,17-$ 19]. Animals were fed with these specific diets for 12 weeks, after which time they were sacrificed under anesthesia. Both tibiae were prepared as follows: skin, muscles and tendons were removed and the fibula was separated at the synostosis. Tibiae were immediately stored at $-80^{\circ} \mathrm{C}$ prior to histological embedding. The metaphysis of the left tibia was used for immunohistochemical investigations as previously described $[6,16]$.

\section{Serum analyses}

Collected blood samples were allowed to clot and then centrifuged at $3,000 \mathrm{~g}, 10 \mathrm{~min}$. Serum concentrations of T and estradiol-17 $\beta$ were quantified using Euless (Roche, Mannheim, Germany) and DSL (Webster, TX, USA) commercial immunoassays, respectively. To avoid the difference in $\mathrm{T}$ and estradiol level, all blood samples are taken at a certain time in the mornings.

\section{BMD measurement}

Twelve weeks after orchidectomy or on supplemented diets with $\mathrm{T}, \mathrm{R}$ and $\mathrm{E}$, total BMD, total bone area (TBA), trabecular density and trabecular area of the proximal tibial metaphysis were recorded by qCT (STRATEC XCT 4.50, Stratec Inc., Pforzheim, Germany) in anesthetized animals. The scanner was positioned in the proximal plane of the left tibial metaphysis and a coronal computed radiograph (Scout view) in the distal direction was carried out. Image acquisition, processing and calculation were performed using the software package (XCT 5.40, STRATEC Inc. Pforzheim, Germany). Trabecular values were calculated by acquiring data within the default threshold of 280 $710 \mathrm{mg} / \mathrm{cm}^{3}$. Cortical area and cortical density were calculated from a slice sampled $15 \mathrm{~mm}$ distal to the growth plate. A density above $710 \mathrm{mg} / \mathrm{mm}^{3}$ was regarded to be cortical bone.

Biomechanical testing

A ZWICK-testing machine type 145660Z020/TND (Zwick/Roell, Ulm, Germany) with a measuring range from 2 to $200 \mathrm{~N}$ at a relative accuracy of $0.2 \%$ at $0.4 \% \mathrm{FN}$ and a newly developed device as previously described [18] were used for mechanical testing of the metaphyseal tibia. Strength admission was recorded using "testXpert" software. The speed of the feed motion was $50 \mathrm{~mm} / \mathrm{s}$ and the 
automatic switch off-pressure was set at $300 \mathrm{~N}$. The left tibiae were thawed and continuously moistened with isotonic saline solution during the test. The procedure was performed blindly with regard to the test groups.

Preparation for microscopy and microradiography

After biomechanical testing, complete tibiae were defatted in an alcohol series, stained with basic fuchsine (ChromaGesellschaft, Koengen, Germany) and embedded in methyl methacrylate. After polymerization, $100 \mu \mathrm{m}( \pm 10)$ thick sections were cut parallel to the surface of the knee joint using a specifically designed diamond-coated saw (Leica SP 1600 saw microtome, Bensheim, Germany) with a blade thickness of $300 \mu \mathrm{m}$. The level of the sections was calculated in order to obtain one specific section corresponding to $2 \mathrm{~mm}$ distal to the growth plate. Therefore, this section corresponds to the qCT slice, as described above. Microradiographies were performed on KODAK Professional Industrex SR45 film (100 NIF) on a Faxitron X-Ray System (Hewlett-Packard, San Diego, CA, USA) as previously described. The bone sections were exposed for $6 \mathrm{~min}$ at $40 \mathrm{kV}$ and the resolution of the images was approximately $0.5 \mu \mathrm{m}$. The film was analyzed qualitatively and quantitatively under the microscope.

Qualitative and quantitative bone morphometry

Quantitative analysis of bone tissue was digitally determined in the microradiographs using the Quantimet system (Leica DM-RXE and Leica QWIN, Bensheim, Germany) after digital imaging with the Leica DC200 camera. The following data were evaluated: TBA, trabecular bone area (Tb.Ar.), percentage of trabecular bone (Tb.P.), trabecular length (Tb.Ln.), number of trabecular nodes (N.Nd.), cortical bone area (Cb.Ar.), percentage of cortical bone, cortical width lateral (Ct.Wi.l.), cortical width medial (Ct.Wi.m.) and the ratio of cancellous bone area and Tb.Ar. The last value represents the trabecular density. Finally, fracture lines from the previously performed biomechanical testing [18] were analyzed qualitatively.

\section{Statistics}

For statistical analyses, the mean values and standard deviations for each parameter were calculated. The differences between the four tested substances were assessed using ANOVA followed by the Tukey-Kramer post hoc test. For determining the correlation between the microradiographic and biomechanical data, Pearson's correlation coefficient $(r)$ was calculated. This value can range from -1.0 to 1.0 (where $-1.0=$ perfect negative correlation, $0.0=$ no correlation and $1.0=$ perfect positive correlation).

\section{Results}

Serum analyses

The mean serum concentration of testosterone in the Ttreated animals was $4.2 \pm 0.8 \mathrm{ng} / \mathrm{ml}$ and in the estradiol$17 \beta$-treated animals, the mean E level was $51.6 \pm 4.6 \mathrm{pg} / \mathrm{ml}$. Both hormone levels fall within the normal circadian physiological range of male and female rats; hence these animals can be referred as normal (positive) controls. There is currently no established method to determine the serum levels of raloxifene.

Body weight

At the time of castration, the average body weight for control animals was $242.8 \pm 7.0 \mathrm{~g}$ and for the T-, R- and E-treated groups, $259.3 \pm 45.2,280.3 \pm 26.1$ and $245.2 \pm$ $13.3 \mathrm{~g}$, respectively. The average body weight of R-treated rats was significantly higher than for control and E-treated animals. Three months after castration, diverse increases in weight were observed amongst the animal groups, the control and T-treated animals weighed $392.8 \pm 19.7 \mathrm{~g}$ $(+38.2 \%)$ and $393.4 \pm 23.4 \mathrm{~g}(+34.1 \%)$, respectively, whereas treatments with $\mathrm{R}$ and $\mathrm{E}$ were associated with a significantly lower animal body weights of $319.3 \pm 22.0 \mathrm{~g}$ $(+12.2 \%)$ and $270.1 \pm 18.9 \mathrm{~g}(+9.3 \%)$, respectively. For E this is a well-known effect [20, 21].

BMD and bone areas (qCT)

Total BMD and bone area, as well as trabecular and cortical areas and densities at the metaphyseal tibia were obtained 3 months after castration and onset of T-, R- or E-supplemented diets. With $\mathrm{T}$ supplementation, only the value "trabecular density" $\left(178.4 \pm 34.61 \mathrm{mg} / \mathrm{cm}^{3}\right)$ showed significant preservation compared with the osteoporotic control group $\left(135.8 \pm 13.24 \mathrm{mg} / \mathrm{cm}^{3}\right)$ (Fig. 1d). Regarding $\mathrm{R}$ - and E-treated bone, a significant enhancement in both total BMD (R: $788.3 \pm 97.24 \mathrm{mg} / \mathrm{cm}^{3}$, E: $765.9 \pm$ $108.6 \mathrm{mg} / \mathrm{cm}^{3}$ ) and trabecular density (R: $186.4 \pm$ $51.42 \mathrm{mg} / \mathrm{cm}^{3}$, E: $175.9 \pm 38.54 \mathrm{mg} / \mathrm{cm}^{3}$ ) was observed compared to the osteoporotic C (tBMD: 701.1 \pm 129.5 $\mathrm{mg} / \mathrm{cm}^{3}$ ). Interestingly, the trabecular areas for the $\mathrm{R}$ $\left(4.12 \pm 1.73 \mathrm{~mm}^{2}\right)$ and $\mathrm{E}$ groups $\left(4.19 \pm 1.84 \mathrm{~mm}^{2}\right)$ were significantly lower than in the control $\left(5.74 \pm 2.51 \mathrm{~mm}^{2}\right)$ and in the $\mathrm{T}$ group $\left(5.70 \pm 2.50 \mathrm{~mm}^{2}\right)$. For $\mathrm{E}$ this is explainable by the significantly lower TBA (E: $11.99 \pm$ $3.12 \mathrm{~mm}^{2}$, C: $14.34 \pm 3.80 \mathrm{~mm}^{2}$; T: $14.16 \pm 4.27 \mathrm{~mm}^{2}$, R: $14.41 \pm 6.86 \mathrm{~mm}^{2}$ ). The values "cortical density" (C: $1,208 \pm 64.58 \mathrm{mg} / \mathrm{cm}^{3}$, T: $1,195 \pm 65.71 \mathrm{mg} / \mathrm{cm}^{3}$, R: $1,237 \pm 98.59 \mathrm{mg} / \mathrm{cm}^{3}$, E: $1,243 \pm 53.29 \mathrm{mg} / \mathrm{cm}^{3}$,) and "cortical area" (C: $6.44 \pm 0.79 \mathrm{~mm}^{2}, \mathrm{~T}: 6.25 \pm 0.66 \mathrm{~mm}^{2}$, 

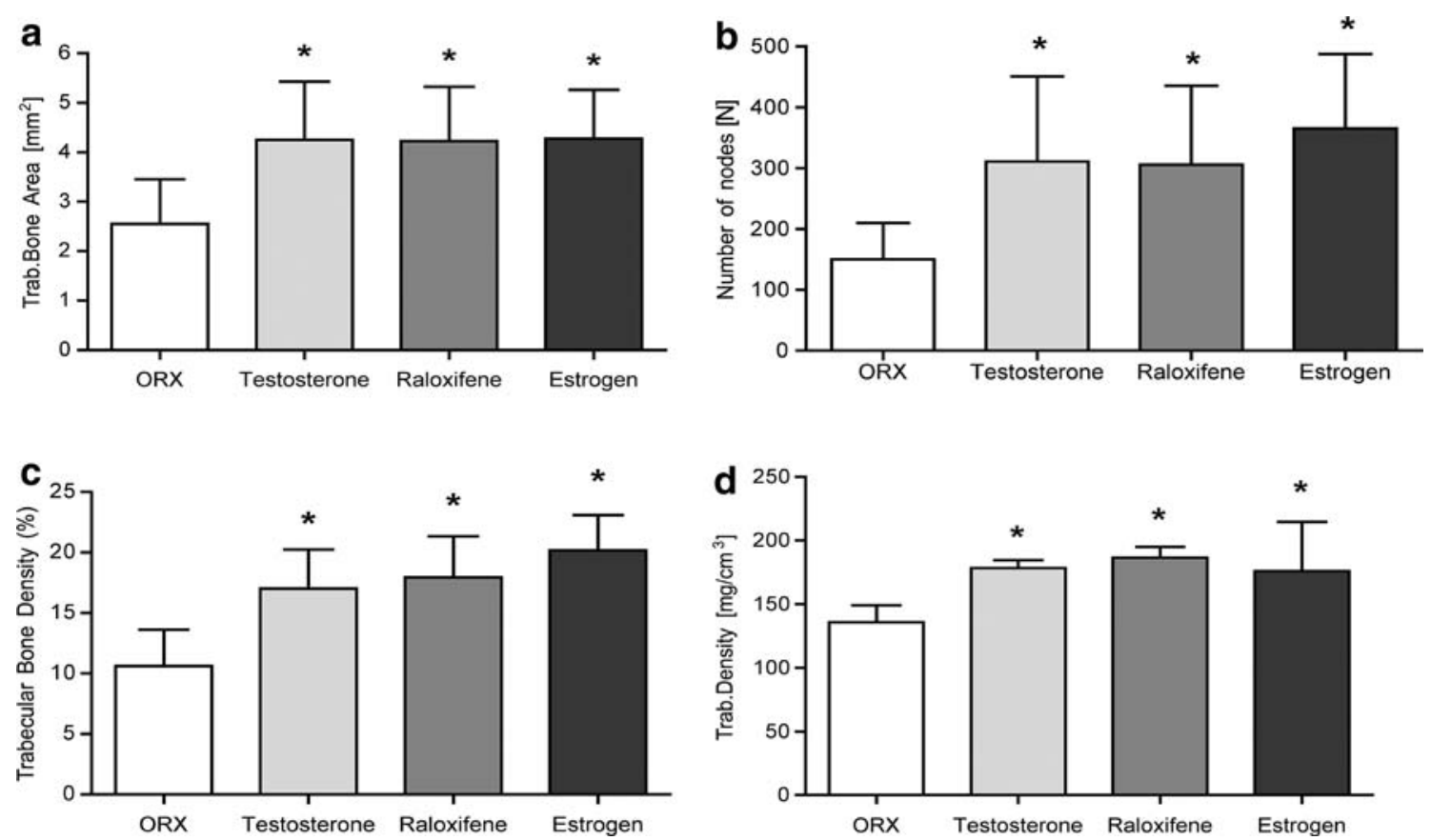

Fig. 1 Analysis of the trabecular structure of the metaphyseal tibia in male rats in the microradiography. a Trabecular bone area $\left(\mathrm{mm}^{2}\right)$, b absolute number of nodes (No) and $\mathbf{c}$ trabecular bone area density

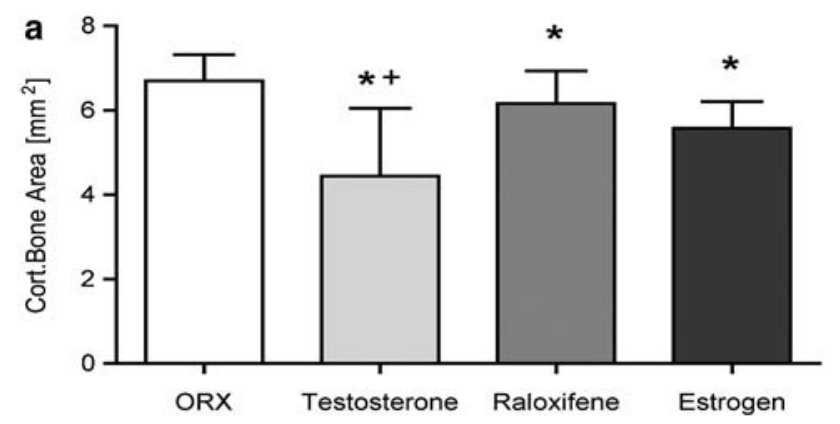

(\%). Comparison to $\mathbf{d}$ trabecular density $\left(\mathrm{mg} / \mathrm{cm}^{3}\right)$ measured by the $\mathrm{qCT}$. Values are expressed as the mean $\pm \mathrm{SD}(* P<0.01$ vs. control, $\# P<0.01$ vs. $\mathrm{E},+P<0.01$ vs. $\mathrm{R})$

Biomechanical testing

On the basis of established strength graphs, the maximum force $\left(F_{\max }\right)$ and yield load $(\mathrm{yL})$ were calculated. The average yield load amounted to $39.5 \pm 15.5 \mathrm{~N}$ for the osteoporotic $\mathrm{C}$ group, $49 \pm 21.4 \mathrm{~N}$ for T-treated, $83.3 \pm 16.5 \mathrm{~N}$ for R-treated and $99.2 \pm 21.1 \mathrm{~N}$ for E-treated animals, respectively. All differences between the test groups regarding the yL were significant (Fig. 3a). The average $F_{\max }$ amounted to $76.7 \pm 12.5 \mathrm{~N}$ for the $\mathrm{C}$ and $74.8 \pm 15.7 \mathrm{~N}$ for the $\mathrm{T}$

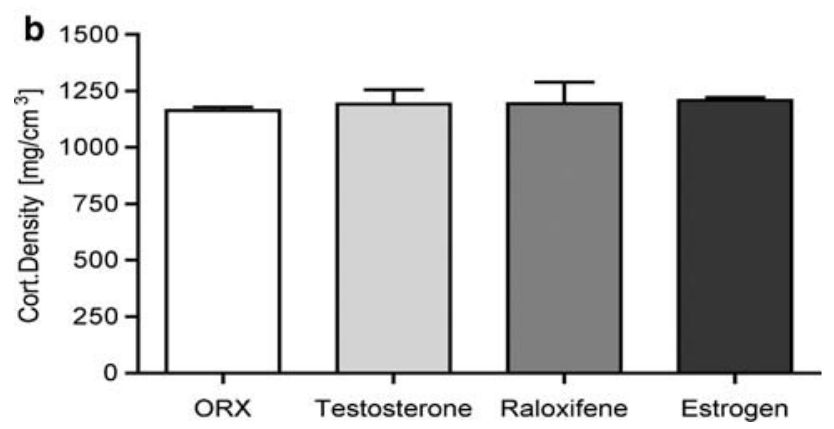

Fig. 2 Analysis of the cortical structure of the tibia in male rats. a Microradiographic evaluation of the metaphyseal cortical bone area $\left(\mathrm{mm}^{2}\right)$, and $\mathbf{b}$ diaphyseal cortical density $\left(\mathrm{mg} / \mathrm{cm}^{3}\right)$ determined by the qCT. Values are expressed as the mean $\pm \mathrm{SD}(* P<0.01$ vs. control, $+P<0.01$ vs. R)

R: $6.97 \pm 2.29 \mathrm{~mm}^{2}$, E: $5.69 \pm 0.69 \mathrm{~mm}^{2}$ ) measured in the qCT were very similar between all animal groups (Fig. 2b). group. They were significantly lower than in the $\mathrm{R}(111.0 \pm$ $10.9 \mathrm{~N})$ and the E groups $(114.3 \pm 17.4 \mathrm{~N})($ Fig. $3 \mathrm{~b})$.

Microradiography and morphometry

A significant improvement in all trabecular values Tb.Ar., Tb.P. and N.Nd. were clearly visible (Fig. 4) and could be detected for all tested substances compared to those values for the osteoporotic control (Table 1; Fig. 1a-c). E versus $\mathrm{R}$ showed only minor differences, whereas $E$ preserved the trabecular bone slightly more (more Tb.P., more N.Nd. and therefore shorter $\mathrm{Tb}$.Ln.). It should be noted that all cortical values (Cb.Ar., Cb.P., Ct.Wi.l. and Ct.Wi.m.) after T supplementation were significantly lower than the R, E and even than the control group (Table 1; Fig. 2a). Under E and $\mathrm{R}$ supplementation, the $\mathrm{Cb}$.Ar.s were also significantly lower than in control animals, but with regard to the TBAs, only the Cb.P. of the $\mathrm{T}$ group showed a significantly lower value (Table 1). Corresponding with these results, the 

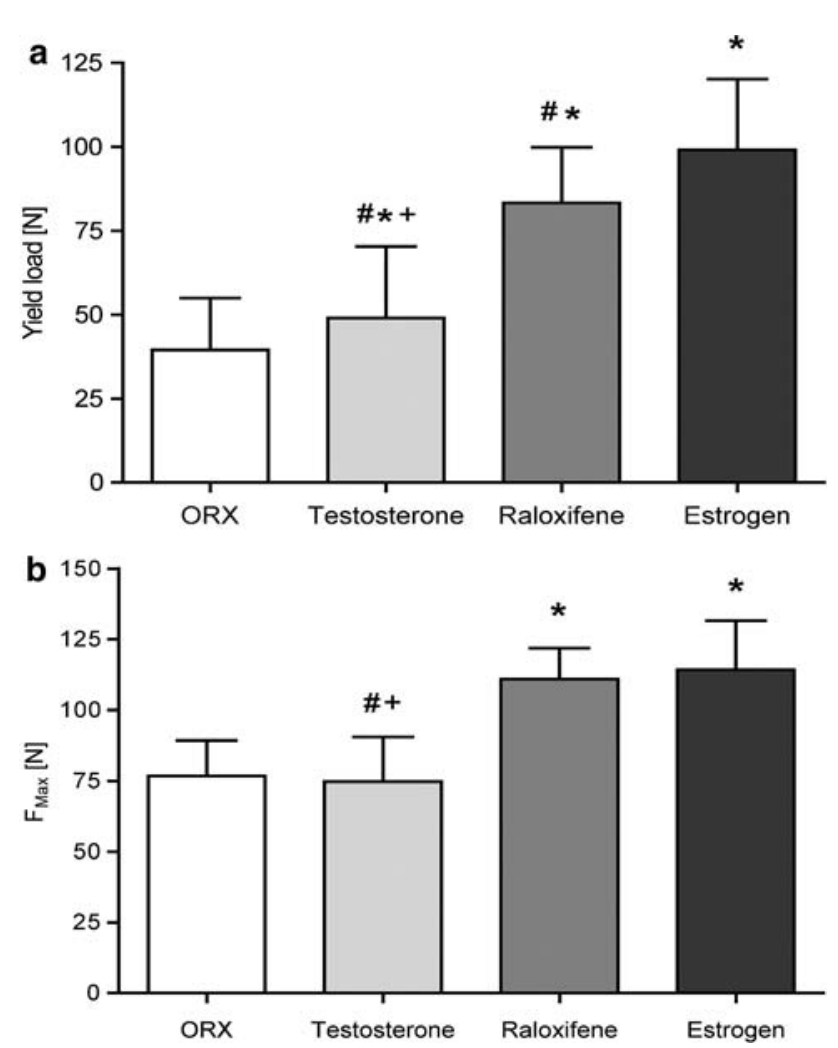

Fig. 3 Results of the biomechanical testing of the metaphyseal tibia in male rats. a Plastic deformation determined by the yield load $(N)$ and b final failure determined by $F_{\max }(N)$. Values are expressed as the mean $\pm \mathrm{SD}(* P<0.01$ vs. control, $\# P<0.01$ vs. $\mathrm{E},+P<0.01$ vs. $\mathrm{R})$

cortical width (Ct.Wi.l., Ct.Wi.m.) was significantly smaller in the $\mathrm{E}$ - and $\mathrm{T}$ group compared to the $\mathrm{C}$ group. For $\mathrm{R}$, the cortical widths were higher than in $\mathrm{C}$; the consideration of the Cb.P. values of $\mathrm{R}$ argues that there is a homogeneous distribution of the cortical bone.

\section{Pearson correlation test}

Table 2 shows the correlation between the microradiographic and biomechanical data of the animal experiments. A significant negative correlation was found between $F_{\max }$, the yield load and the TBA, respectively. $F_{\max }$ also correlated in a significant but positive manner with the cortical width, density of the trabecular bone and trabecular length. The yield load correlated significantly with nearly all trabecular values. In summary, elasticity and the avoidance of microfracturing, depend on the trabecular network, whereas the occurrence of a visible fracture depends on the combination of all bone parameters (TBA, cortical and trabecular bone).

Analysis of the post-mortem fracture lines

Examination of the microradiographs allowed the differences in the fracture lines from the biomechanical testing to be determined in all groups. In an example picture from an osteoporotic control (Fig. 4a, e), the main fracture line is clearly visible. In this group fracture lines failed in a burstlike fashion with no regard for the bone architecture and matrix. In contrast, in the E-supplemented group, the main fracture line spread with many comminutions of various lengths (Fig. $4 \mathrm{~d}, \mathrm{~h}$ ) and the force appeared to propagate directly through those bone structures with least resistance (i.e., the fracture "cuts" through the thinnest trabecular junctions). In the $\mathrm{R}$ group (Fig. $4 \mathrm{c}, \mathrm{g}$ ), this phenomenon was less developed compared to the $\mathrm{E}$ group, although more visible. After $\mathrm{T}$ supplementation, less comminution were found, although the trabecular network was nearly as dense as those present in R- and E-treated bones (Fig. 4b, f). However, the administered force affected the trabecular structures more than in the other groups because of the weaker cortical bone.

\section{Discussion}

Management of hypogonadism and its related morbidities in male is still a dilemma in medicine. Hypogonadism has been accepted as a significant risk factor for the development of male osteoporosis. However, studies regarding therapy of osteoporosis in males are rare in comparison to those of postmenopausal females. The orchidectomized rat is currently an accepted animal model of male hypogonadism and osteoporosis [22, 23].

\section{Tested substances}

The effects of testosterone may be mediated directly by the androgen receptor or indirectly, via aromatization into estrogens and subsequent stimulation of estrogen receptors (ER- $\alpha$ and ER- $\beta$ ) [24, 25]. It preserved the trabecular structure (Tr.Ar., N.Nd.) significantly compared to the osteoporotic control. The protective effect was nearly as good as for estrogen and raloxifene (Fig. 1a,b). The investigation of the metaphyseal cortical bone in the microradiography showed interesting results regarding testosterone. In contrast to results described by other authors [23-25], a significant deterioration in cortical bone was found after $\mathrm{T}$ supplementation. Cortical bone was more reduced than in the R- and E-treated groups, even more than in the osteoporotic control. The reason for this lack of conformity may be that metaphyseal (tibial) bone was investigated instead of diaphyseal bone, as was investigated in these other previous studies. A possible explanation for this phenomenon may be that the cortical bone has less androgen and/or estrogen receptors, but that has not been proved yet.

The structural changes after testosterone-supplementation could explain the comparatively poor results in the 
Fig. 4 Microradiographic sections of the metaphyseal tibia made $2 \mathrm{~mm}$ distal to the growth plate of the tibia from an a osteoporotic control animal (ORX), b testosterone (T)-, c raloxifene ( $\mathrm{R})$ - and $\mathbf{d}$ estradiol (E)-treated rat, viewed under 30-fold (a-d) and 60-fold (e-h) magnification. Bursting of the osteoporotic bone with additional rupture of the lateral and medial cortical bone (a, e), winding fracture lines with a various number of comminutions in the treatment groups. Decreasing destruction of the bone from $\mathbf{f}$ the $\mathrm{T}-$ to $\mathbf{g}$ the $\mathrm{R}$ - up to $\mathbf{h}$ the E group
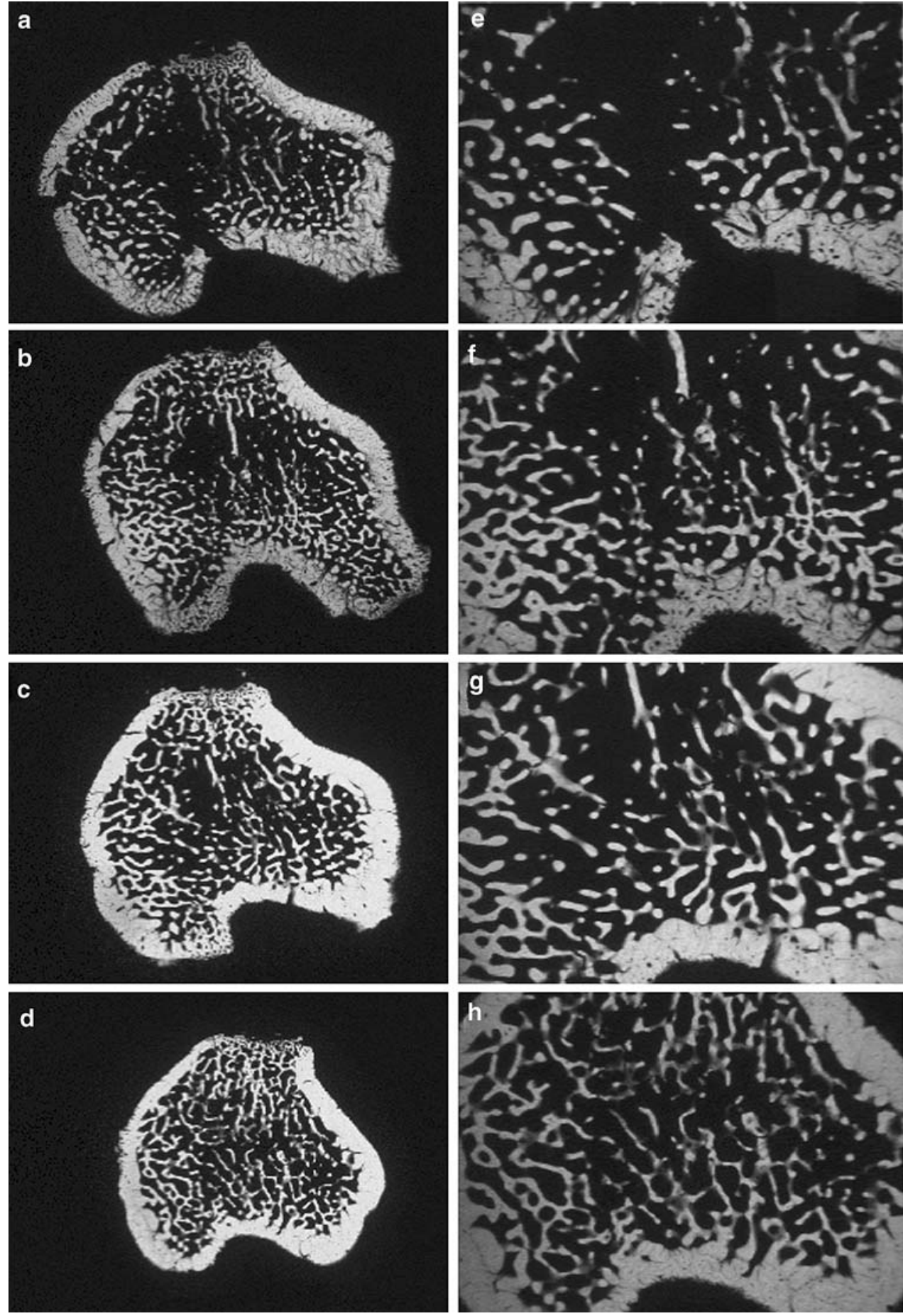

biomechanical tests (Fig. 3). The reduced cortical bone failed early and led to a low $F_{\max }$. However, the dense trabecular structure (Tr.Ar., N.Nd.) did protect the bone since it had high elasticity. Therefore, the $\mathrm{yL}$ is significantly higher than in the osteoporotic C. Microfracturing, which is the basis of the osteoporotic fracture, occurred later in $\mathrm{T}$ than in $\mathrm{C}$. These data suggest that if $\mathrm{T}$ is to be used in treatment of osteoporosis, it needs to be supplemented by another bone-sparing substance, i.e., bisphosphonates as an osteoclast inhibitor.

Estrogen plays a key role in male skeletal growth $[26,27]$. In this study preserved the trabecular bone more than T and R. It is well-acknowledged that estrogen application in rats' results in smaller animals with a lower body weight [27]. Therefore, the significantly smaller TBA must be taken into consideration; the number of nodes and 
Table 1 Morphological analysis of the cortical and trabecular bone in the microradiographic sections 2 mm distally to the growth plate in the metaphyseal tibia in male rats

\begin{tabular}{lcccc}
\hline & Osteoporotic control & Testosterone & Raloxifene & Estrogen \\
\hline Total bone area $\left(\mathrm{mm}^{2}\right.$; mean) & $23.66 \pm 2.26$ & $24.67 \pm 3.11$ & $23.37 \pm 3.39$ & $20.99 \pm 2.54^{\mathrm{a}}$ \\
Trabecular bone area $\left(\mathrm{mm}^{2}\right.$; mean) & $2.553 \pm 0.90$ & $4.253 \pm 1.18^{\mathrm{a}}$ & $4.223 \pm 1.10^{\mathrm{a}}$ & $4.276 \pm 0.99^{\mathrm{a}}$ \\
Percentage of trabecular bone $(\%$; mean) & $10.62 \pm 2.994$ & $17.01 \pm 3.223^{\mathrm{a}}$ & $17.95 \pm 3.371^{\mathrm{a}}$ & $20.18 \pm 2.909^{\mathrm{a}}$ \\
Trabecular bone area/cancellous bone area ratio & $7.40 \pm 3.01$ & $4.87 \pm 0.68^{\mathrm{a}}$ & $4.19 \pm 0.71^{\mathrm{a}}$ & $3.70 \pm 0.53^{\mathrm{a}}$ \\
$\quad($ Tb.Ar./Cn.Ar.) (mean) & $102.7 \pm 7.28$ & $99.45 \pm 5.11$ & $108.2 \pm 9.74$ & $103.2 \pm 5.88$ \\
Trabecular length $(\mu \mathrm{m}$; mean) & $150.3 \pm 59.87$ & $311.1 \pm 140.10^{\mathrm{a}}$ & $306.1 \pm 129.40^{\mathrm{a}}$ & $365.6 \pm 122.20^{\mathrm{a}}$ \\
Number of nodes (mean) & $6.701 \pm 0.62$ & $4.443 \pm 1.61^{\mathrm{a}}$ & $6.165 \pm 0.77^{\mathrm{a}}$ & $5.575 \pm 0.64^{\mathrm{a}}$ \\
Cortical bone area (mm ; mean) & $28.59 \pm 3.98$ & $18.68 \pm 8.41^{\mathrm{a}}$ & $30.02 \pm 4.41$ & $26.77 \pm 3.10$ \\
Percentage of cortical bone $(\%$ mean) & $457.7 \pm 48.29$ & $388.0 \pm 48.29^{\mathrm{a}}$ & $498.6 \pm 36.87^{\mathrm{a}}$ & $396.2 \pm 23.74^{\mathrm{a}}$ \\
Cortical width lateral $(\mu \mathrm{m}$; mean) & $324.1 \pm 21.33$ & $254.4 \pm 41.95^{\mathrm{a}}$ & $349.0 \pm 42.60$ & $273.8 \pm 34.68^{\mathrm{a}}$ \\
Cortical width medial $(\mu \mathrm{m}$; mean) & & & & \\
\hline
\end{tabular}

${ }^{a}$ Significant versus ORX control group

Table 2 Positive and negative correlations of the morphological data of the microradiographies and biomechanical testing evaluated in the Pearson test

Pearson $r$ and $R^{2}$, representing the percentage of correlating values

$* P<0.005$

\begin{tabular}{|c|c|c|c|c|}
\hline & \multicolumn{2}{|l|}{$F_{\max }$} & \multicolumn{2}{|l|}{ Yield load } \\
\hline & Pearson $r$ & $R^{2}$ & Pearson $r$ & $R^{2}$ \\
\hline Total bone area & $-0.4964 *$ & $0.2464 *$ & $-0.2937 *$ & $0.0863 *$ \\
\hline Trabecular bone area & 0.1665 & 0.0277 & $0.4030 *$ & $0.1624 *$ \\
\hline Tb.Ar./Cn.Ar. ratio & $0.5531 *$ & $0.3060^{*}$ & $0.6186^{*}$ & $0.3826 *$ \\
\hline Number of nodes & 0.1885 & 0.0355 & $0.4773 *$ & $0.2279 *$ \\
\hline Trabecular length & $0.3212 *$ & $0.1032 *$ & 0.2001 & 0.0400 \\
\hline Cortical bone area & -0.2800 & 0.0784 & -0.2736 & 0.0749 \\
\hline Percentage of cortical bone & 0.2656 & 0.0706 & 0.1429 & 0.0204 \\
\hline Average cortical width & $0.3226^{*}$ & $0.1041 *$ & -0.0407 & 0.0016 \\
\hline
\end{tabular}

relation of trabecular volume to tissue volume to cancellous volume were remarkably high. However, supplementation of $\mathrm{E}$ does not seem to improve the cortical bone in comparison to $\mathrm{C}$. When considering biomechanical features, this had no negative effect since the comparable thin cortical bones seemed to have good elasticity and resistance to forces. The measured $\mathrm{yL}$ for $\mathrm{E}$ was the highest and significantly better than for $\mathrm{C}, \mathrm{T}$ and R. Plastic deformation and microfracturing occurred very late. In terms of $F_{\max }$, the bone quality was significantly better than in $\mathrm{C}$ and $\mathrm{T}$; only $\mathrm{R}$ showed equal results to $\mathrm{E}$. E protected the physiological bony structure with a defined mixture of elastic and calcified tissues.

The SERM raloxifene that had been proved to prevent postmenopausal osteoporosis $[9,10]$ was also investigated. It did not bind to androgen receptors, had no effects on male reproduction (sperm production/quality, testicular weight and histopathology) [11] and had positive effects on the serum cholesterol [11] and the elasticity of vessels [21]. Therefore, it may also be a good option in the treatment of osteoporosis in males. In osteoporotic rats, it mimicked most preserving effects of $\mathrm{E}$, but did not yet reach the levels that $\mathrm{E}$ did in all parameters. Supplementation of $\mathrm{R}$ preserved the structure of the osteoporotic bones significantly. This was true for the metaphyseal cortical bone as well as the trabecular bone. In comparison to $\mathrm{E}, \mathrm{R}$ preserved cortical bone more, but the trabecular bone was preserved less well than E. Overall, the bone volume (per tissue volume) was highest in R. That supports the well-acknowledged fact that the structure of bone is more important than the bone mass regarding the question of capacitance. The final failure $\left(F_{\max }\right)$ for $\mathrm{R}$ was equal to $\mathrm{E}$. But the yield load, which is more interesting in osteoporosis, was significantly lower than in E. Fatigue fractures in osteoporosis as the result of the sum of microfractures would occur significantly earlier. Regarding the prophylaxis of osteoporosis E outperforms R.

Morphological methods

The morphological analysis with the $\mathrm{qCT}$ and microradiography showed that the tested substances $\mathrm{T}, \mathrm{R}$ and $\mathrm{E}$ improved the trabecular structure. The $\mathrm{qCT}$ seemed to be less qualified for analysis of the minor metaphyseal cortical 
bone. Microradiography was able to illustrate the different influences of the tested substances more precisely.

In clinical practice, microscopic evaluation or non-invasive biomechanical measurement of bone quality for diagnostics or therapy of osteoporosis is not possible. It is wellknown that the true individual risk of fracture cannot be measured by BMD alone. However, there is yet to be an alternative device for estimating individual bone quality in vivo. Micro-CTs for clinical examinations of human bone are rare worldwide. They provide more detailed, but also indirect parameters to estimate fracture risk. In the future, it may be helpful to also investigate the non-calciferous bone matrix and its changes during developing osteoporosis (e.g., by an exploratory excision) because of its important influence on the elasticity and brittleness of bone.

\section{Conclusion}

Testosterone only improved the trabecular bone structure, however due to the loss of cortical bone, fragility was nearly the same as that for osteoporotic bone. $\mathrm{R}$ had a good effect and hindered the bone loss associated with osteoporosis at trabecular structures. However, its effect did not approach the protective effect of $\mathrm{E}$ on the incidence of microfractures, which form the basis of osteoporotic fractures. E inhibited growth and induced smaller tibiae in rat, which was also advantageous. Nevertheless, Raloxifene may be a potential male osteoporosis treatment, as estrogen cannot be used in males because of its feminizing effects.

\section{Conflict of interest statement There is no conflict of interest.}

Open Access This article is distributed under the terms of the Creative Commons Attribution Noncommercial License which permits any noncommercial use, distribution, and reproduction in any medium, provided the original author(s) and source are credited.

\section{References}

1. Nabel EG (2006) The women's health initiative. Science 313:1703. doi:10.1126/science.1134995

2. Seidlova-Wuttke D, Hesse O, Jarry H, Christoffel V, Spengler B, Becker T, Wuttke W (2003) Evidence for selective estrogen receptor modulator activity in a black cohosh (Cimicifuga racemosa) extract: comparison with estradiol-17beta. Eur J Endocrinol 149:351-362. doi:10.1530/eje.0.1490351

3. Bland R (2000) Steroid hormone receptor expression and action in bone. Clin Sci 98:217-240. doi:10.1042/CS19990252

4. Lindberg MK, Moverare S, Skrtic S, Alatalo S, Halleen J, Mohan S, Gustafsson JA, Ohlsson C (2002) Two different pathways for the maintenance of trabecular bone in adult male mice. J Bone Miner Res 17:555-562. doi:10.1359/jbmr.2002.17.4.555

5. Yanase T, Suzuki S, Goto K, Nomura M, Okabe T, Takayanagi R, Nawata H (2003) Aromatase in bone: role of vitamin D3 and androgens. J Steroid Biochem Mol Biol 86:393-397. doi:10.1016/ S0960-0760(03)00349-2

6. Seidlova-Wuttke D, Sturmer KM, Sturmer EK, Sehmisch S, Wuttke W (2006) Contrasting effects of estradiol, testosterone and of black cohosh extract on density, mechanical properties and expression of several genes in the metaphysis of the tibia and on fat tissue of orchidectomized rats. Maturitas 55:64-74. doi:10. 1016/j.maturitas.2006.06.018

7. Matsumoto C, Inada M, Toda K, Miyaura C (2006) Estrogen and androgen play distinct roles in bone turnover in male mice before and after reaching sexual maturity. Bone 38:220-226. doi:10. 1016/j.bone.2005.08.019

8. Murata Y, Robertson KM, Jones MEE, Simpson ER (2002) Effect of estrogen deficiency in the male: the ArKO mouse model. Mol Cell Endocrinol 193:7-12. doi:10.1016/S0303-7207(02)00090-4

9. Clemett D, Spencer CM (2000) Raloxifene: a review of its use in postmenopausal osteoporosis. Drugs 60:379-411. doi:10.2165/ 00003495-200060020-00013

10. Reginster JY, Devogelaer JP (2006) Raloxifene reduces fractures in postmenopausal women with osteoporosis. Clin Orthop Relat Res 443:48-54. doi:10.1097/01.blo.0000200234.99436.24

11. Buelke-Sam J, Bryant HU, Francis PC (1998) The selective estrogen receptor modulator raloxifene: an overview of nonclinical pharmacology and reproductive and developmental testing. Reprod Toxicol 12:217-221. doi:10.1016/S0890-6238(98)00003-3

12. Wronski TJ, Yen CF (1991) The ovariectomized rat as an animal model for postmenopausal bone loss. Cells Mater 1(Suppl 1):69_ 74

13. Frost HM, Jee WS (1992) On the rat model of human osteopenias and osteoporoses. Bone Miner 18:227-236. doi:10.1016/01696009(92)90809-R

14. Wronski TJ, Lowry PL, Walsh CC, Ignaszewski LA (1985) Skeletal alterations in ovariectomized rats. Calcif Tissue Int 37:324-328. doi:10.1007/BF02554882

15. Thompson DD, Simmons HA, Pirie CM, Ke HZ (1995) FDA Guidelines and animal models for osteoporosis. Bone 17:125S133S. doi:10.1016/8756-3282(95)97353-H

16. Thurner PJ, Wyss P, Voide R, Stauber M, Stampanoni M, Sennhauser U, Muller R (2006) Time-lapsed investigation of three-dimensional failure and damage accumulation in trabecular bone using synchrotron light. Bone 39:289-299. doi:10.1016/ j.bone.2006.01.147

17. Stuermer EK, Seidlova-Wuttke D, Sehmisch S, Rack T, Wille J, Frosch KH, Wuttke W, Stuermer KM (2006) Standardized bending and breaking test for the normal and osteoporotic metaphyseal tibias of the rat: effect of estrogen, testosterone and raloxifene. J Bone Miner Res 21:89-96. doi:10.1359/JBMR.050913

18. Cao Y, Mori S, Mashiba T, Westmore MS, Ma L, Sato M, Akiyama T, Shi L, Komatsubara S, Miyamoto K, Norimatsu H (2002) Raloxifene, estrogen and alendronate affect the processes of fracture repair differently in ovariectomized rats. J Bone Miner Res 17:2237-2246. doi:10.1359/jbmr.2002.17.12.2237

19. Bolander ME, Sabbagh R, Jeng C, Vivianno D, Boden SD (1992) Estrogen treatment during fracture repair strengthens healing callus in an osteoporotic model. Trans Orthop Res Soc 17:138

20. Juul A (2001) The effects of oestrogens on linear bone growth. Hum Reprod Update 7:303-313. doi:10.1093/humupd/7.3.303

21. MacGillivray MH, Morishima A, Conte F, Grumbach M, Smith EP (1998) Pediatric endocrinology update: an overview. The essential roles of estrogens in pubertal growth, epiphyseal fusion and bone turnover: lessons from mutations in the genes for aromatase and the estrogen receptor. Horm Res 49:2-8. doi:10.1159/ 000053061

22. Verhas M, Schoutens A, L'hermitie-Baleriaux M, Dourov N, Verschaeren A, Mone M, Heilporn A (1986) The effect of 
orchidectomy on bone metabolism in aging rats. Calcif Tissue Int 39:74-77. doi:10.1007/BF02553294

23. Wink C, Felts WJL (1980) Effects of castration on the bone structure of male rats: a model of osteoporosis. Calcif Tissue Int 32:7782. doi:10.1007/BF02408524

24. Prakasam G, Yeh JK, Chen MM, Castro-Magana M, Liang CT, Aloia JF (1999) Effects of growth hormone and testosterone on cortical bone formation and bone density in aged orchiectomized rats. Bone 24:491-497. doi:10.1016/S8756-3282(99)00018-6

25. Turner RT, Wakley GK, Hannon KS (1990) Differential effects of androgens on cortical bone histomorphometry in gonadectomized male and female rats. J Orthop Res 8:612-617. doi:10.1002/ jor. 1100080418
26. Venken K, De Gendt K, Boonen S, Ophoff J, Bouillon R, Swinnen JV, Verhoeven G, Vanderschueren D (2006) Relative impact of androgen and estrogen receptor activation in the effects of androgens on trabecular and cortical bone in growing male mice: a study in the androgen receptor knockout mouse model. J Bone Miner Res 21:576-585. doi:10.1359/jbmr.060103

27. Vandenput L, Boonen S, Van Herck E, Swinnen JV, Bouillon R, Vanderschueren D (2002) Evidence from the aged orchidectomized male rat model that 17 beta-estradiol is a more effective bone-sparing and anabolic agent than 5alpha-dihydrotestosterone. J Bone Miner Res 17:2080-2086. doi:10.1359/jbmr.2002. 17.11.2080 